Available online at GSC Online Press Directory

GSC Advanced Research and Reviews e-ISSN: 2582-4597, CODEN (USA): GARRC2

Journal homepage: https://www.gsconlinepress.com/journals/gscarr

(RESEARCH ARTICLE)

\title{
Effect of alpha-cypermethrin on serotonin, nor-epinephrine and brain changes in rats
}

\author{
Kaoud Hussein A ${ }^{1,}{ }^{*}$, Elsaied Ahmed $\mathrm{H}^{2}$ and Khalil Maged A ${ }^{3}$ \\ ${ }^{1}$ Dept. of Veterinary Hygiene and Environmental Pollution, Faculty of Veterinary Medicine, Cairo University, Egypt. \\ 2 Researcher in Dept. of Pharmaceuticals Biotechnology, Martin Luther King College, Germany. Email. \\ ${ }^{3}$ Researcher in Dept. of Hygiene and Environmental Pollution, Faculty of Veterinary Medicine, Cairo University, Egypt.
}

Publication history: Received on 13 July 2020; revised on 29 July 2020; accepted on 30 July 2020

Article DOI: https://doi.org/10.30574/gscarr.2020.4.1.0060

\begin{abstract}
In the present study, brain damages, serotonin and nor-epinephrine activity on rat brain were investigated. A single sub-acute lethal -oral dose of Alpha-Cypermethrin ( $\left.25 \mathrm{mg} \mathrm{kg}^{-1}\right)$ was given to rat. Blood and brain tissue samples were examined biologically and histopathologically at various times $(1,2,3,4$ and $24 \mathrm{~h})$ after dosing. Results revealed that extracellular serotonin levels \% (f mol/mg tissue) in rat ventral hippocampus at $25 \mathrm{mg} \mathrm{kg}^{-1} \mathrm{~B} . \mathrm{W}$. After 1, 2, 3 and $24 \mathrm{hr}$. were $105 \pm 4,80 \pm 7,80 \pm 4,70 \pm 4$, respectively. While extracellular NA levels after 1, 2, 3 and $24 \mathrm{hr}$. were $300 \pm 10,450$ $\pm 14,400 \pm 12,400 \pm 11$, respectively. Alpha-cypermethrin acts as nor-epinephrine reuptake inhibitors (NRIs) and serotonin reuptake stimulator in rat brain. The lesions in the brain of the treated groups were gliosis, perineuronal vacuolation, perivascular vacuolation, and neuronal degeneration.
\end{abstract}

Keywords: Brain Damage; Alpha-Cypermethrin; Acute Sub-Lethal Dose; Serotonin; Nor-epinephrine.

\section{Introduction}

Cypermethrin, an alpha-cyano-3-phenoxybenzyl ester of 2,2-dimethyl-3 (2,2-dichlorovinyl) cyclopropane carboxylic acid, is one of the most commonly used pyrethroid II pesticides. It is an artificial compound pyrethroid, broad spectrum, biodegradable insecticide, and fast-acting neurotoxin with good contact and stomach action. It is used to control many pest infestations. In cases of accidental or deliberate ingestion of relatively large amounts of solutions containing pyrethroids, signs of neurotoxicity such as headache, muscle crumbs, convulsions, and coma have been reported [1,2].

The synthetic pyrethroids delay closure of the sodium channel, resulting in a sodium tail current that is characterized by a slow influx of sodium during the end of depolarization. Apparently the pyrethroid molecule holds the activation gate in the open position. Pyrethroids with an alpha-cyano group (e.g., fenvalerate) produce more prolonged sodium tail currents than do other pyrethroids (e.g., permethrin, bioresmethrin). The former group of pyrethroids causes more cutaneous sensations than the latter. /Synthetic pyrethroids/ [3].

Synthetic pyrethroids delay the closure of the sodium channel, resulting in a sodium tail stream characterized by a slow sodium flow during the end of depolarization. The pyrethroid molecule appears to stop an activation gate in open mode. Pyrethroids with the alpha cayano group (for example, fenvalerate) produce more sodium tail streams for longer periods than other pyrethroids (such as permethrin and bioremethrin). The previous group of pyrethroids cause more skin sensations than the latter. / Synthetic pyrethroids [3].

Pyrethroids Type II can inhibit the specific binding at or near the picrotoxin site of GABAA receptors in the brain of mic [4,5], and in particular inhibit the flow of GABA-based chloride [6].

\footnotetext{
* Corresponding author: Kaoud Hussein A
} 
Synthetic pyrethroids are used to protect animals, crops, and humans from a wide range of pests [7]. In recent years, the application of compounds has increased several -fold due to their lower mammalian toxicity and limited soil constancy compared to organochlorine insecticides [8].

The purpose of present study was to extend our knowledge of the action of cypermethrin on brain tissue in an animal model. The aging human population is chronically exposed to cypermethrin through food consumption (pesticide residues) in food, drinking water from dug wells, deep wells and water mains in rural areas. Therefore, study of an extremely interesting issue of practical significance.

\section{Material and methods}

\subsection{Experimental animals}

48 males of the Wistar rats were used, weighing between 180 and $200 \mathrm{~g}$. According the standard protocol, all rats were housed in a quiet, non-stressful environment for one week prior to the study. Rats were divided into two main groups (alpha -cypermethrin treated group and control group)

Animals were housed in the Animals House Unit in Faculty of Veterinary Medicine, Cairo University. They were kept in plastic cages with stainless steel wire lids; (bedded with wood shavings); on a standard laboratory feed diet. Animals were housed at constant room temperature $\left(20-22^{\circ} \mathrm{C}\right), 60 \%$ humidity and light cycle of $12 \mathrm{~h}$. /day. All rats were given 45-50 kcal/day normal rat chows during the experimental period. Animal care as well as the experimental procedures was in compliance with guidelines of ethical standards released by Cairo university policy on Animal Care and Use. In order to minimize animal's suffering, we intended only to use the adequate minimal number of animals requested to produce reliable scientific data. All efforts were made to minimize the number of animals and their suffering in this study through following the guidelines released by Cairo university policy on Animal Care and Use.

The Alpha-Cypermethrin treated group, $(n=20)$ were received Alpha-Cypermethrin orally by gavages at a dose of 25 $\mathrm{mg} \mathrm{kg}{ }^{-1}$.

Control group, $(n=20)$.

\subsection{Sampling}

Blood samples were drawn by cardiac puncture at constant intervals; $1 \mathrm{hr}$., $2 \mathrm{hr}$., $3 \mathrm{hr}$. and $24 \mathrm{hr}$. respectively (four of each time) from the two main groups.

Brain samples were taken at constant intervals; $1 \mathrm{hr}$., $2 \mathrm{hr}$., $3 \mathrm{hr}$. and $24 \mathrm{hr}$. respectively, (four of each time) from the two main groups.

\subsection{Determination of Alpha-Cypermethrin concentration in Blood plasma}

Cypermethrin concentration was determined on an Agilent 7890A gas chromatography (GC) equipped with an electron capture detector (ECD) and a HP-5 capillary column ( $30 \mathrm{~m} \times 0.32 \mathrm{~mm} \times 0.25 \mu \mathrm{m})$. The injector was open at $280^{\circ} \mathrm{C}$ with an injection volume of $1 \mu$ l. the oven temperature was programmed to ramp from 100 to $275^{\circ} \mathrm{C}$ at a rate of $15^{\circ} \mathrm{C} \min ^{1}$.

Recoveries of cypermethrin at different fortification levels, i.e., $0.05,0.1,0.5$ and $1 \mu \mathrm{g} \mathrm{mL}^{1}$, were determined in five replicates to validate and evaluate the accuracy of the method. The recoveries obtained were in the acceptable range 80.8-88.4\%. The coefficient variation of the methods (CV \%) for repeatability ranged from $5.1 \%$ to $13.9 \%$, within acceptable range. The limit of detection (LOD) was estimated to be $0.001 \mu \mathrm{g} \mathrm{mL}^{-1}$ of the tested pesticide, based on signalto-noise ratio 3:1, and the limit of quantification (LOQ) of cypermethrin was $0.005 \mu \mathrm{g} \mathrm{mL}^{-1}$, which yields a signal-tonoise ratio of 10 .

\subsection{Determination of the concentrations of 5-HT(Serotonin) and NA (Noradrenaline) in brain regions}

Analytics: Concentrations of 5-HT and NA were determined within the same samples by HPLC separation and electrochemical detection [9]. Each sample was divided into two subsamples; one was used for 5-HT and other for NA analysis. Aliquots were injected onto the high-performance liquid chromatography (HPLC) column (Gilson, model 832). 


\subsection{Histopathological Investigation}

Brain samples were excised, wiped with brine and then stabilized in 10\% buffered formalin PH 7.0 (phosphate sprayer). In short, fixed specimens were dried and dehydrated, cleared in xylene and embedded in paraffin wax. The blocks were made, and $4 \mu \mathrm{m}$-thick sections were cut using a sledge microtome. Paraffin has been removed from sections of brain tissue and moistened and stained with hematoxylin and eosin (H\&E). Stained slides were examined using a bright field light microscope to investigate the histological alteration in the structure of the brain.

\subsection{Statistical analysis}

SAS. (2000). (Statistical Analysis System, Version 9.2): SAS Institute Inc., Cary, NC 27513-2414 USA [10].

\section{Results and discussion}

Table 1 Concentrations of alpha-cypermethrin oral sub-lethal dose in blood plasma of rats given sub-lethal oral doses (25 mg kg-1 BW).

\begin{tabular}{ll}
\hline Time & Alpha-Cypermethrin \\
\hline $1 \mathrm{hr}$ & $0.416 \pm 0.15$ \\
$2 \mathrm{hr}$ & $0.233 \pm 0.058$ \\
$3 \mathrm{hr}$ & $0.162 \pm 0.058$ \\
$24 \mathrm{hr}$ & $0.257 \pm 0.158$ \\
\hline
\end{tabular}

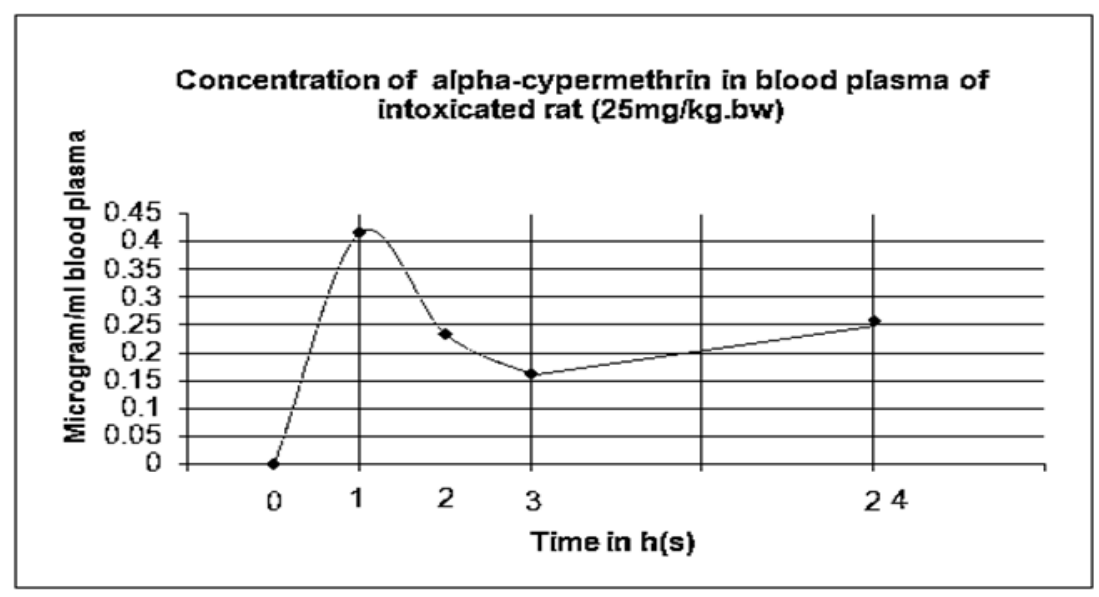

Figure 1 Concentrations of alpha-cypermethrin oral sub-lethal dose in blood plasma of rats given sub-lethal oral doses (25 mg kg-1 BW).

Table 2 Effects of alpha-cypermethrin oral sub-lethal dose on the extracellular serotonin and noradrenalin levels in rat ventral hippocampus.

\begin{tabular}{lllll}
\hline Time & \multicolumn{2}{l}{$\begin{array}{l}\text { Alpha-cypermethrin oral sub-lethal dose } \\
\text { ¥Noradrenalin }\end{array}$} & $\begin{array}{l}\text { Control } \\
\text { Noradrenalin }\end{array}$ & Serotonin \\
\hline $1 \mathrm{hr}$. & $300 \pm 10$ & $105 \pm 4$ & $302 \pm 23$ & $60.8 \pm 33$ \\
$2 \mathrm{hr}$. & $450 \pm 14$ & $80 \pm 7$ & $350 \pm 12$ & $58 \pm 7$ \\
$3 \mathrm{hr}$ & $400 \pm 12$ & $80 \pm 4$ & $300 \pm 12$ & $60 \pm 45$ \\
$24 \mathrm{hr}$. & $400 \pm 11$ & $70 \pm 4$ & $350 \pm 33$ & $59.3 \pm 42$ \\
\hline \multicolumn{5}{c}{} \\
& $¥:$ Basal level \% (f mol/mg tissue: femoto mol).
\end{tabular}



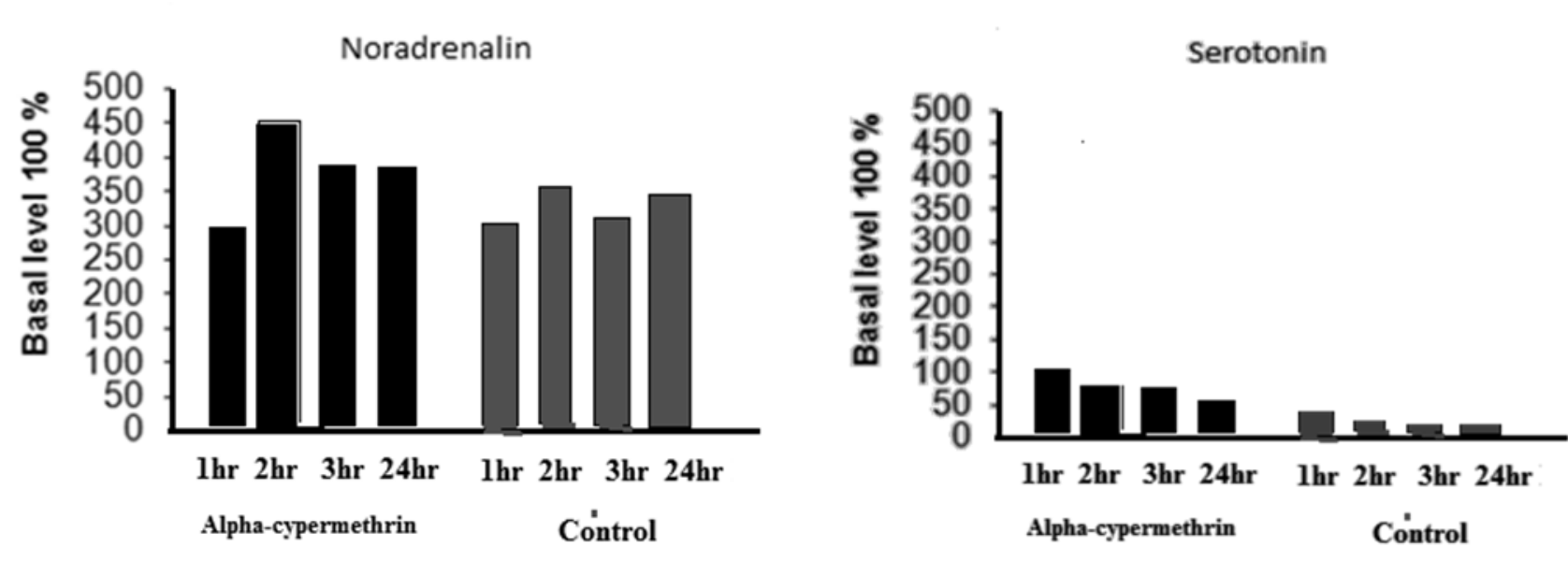

Figure 2 Effects of alpha-cypermethrin oral sub-lethal dose on the extracellular serotonin and noradrenalin levels in rat ventral hippocampus.

Table 3 Effects of Alpha-cypermethrin on the binding of [ $\left.{ }^{3} \mathrm{H}\right] \mathrm{RX} 821002$ to $\alpha_{2}$-adrenergic receptors in the rat brain $(2$ hours post treatment).

\begin{tabular}{lll}
\hline Brain region & Control & Alpha-cypermethrin (mg kg-1 B.W.) \\
\hline Hippocampus formation & $61.40 \pm 2.63$ & $65.2 \pm 3.42 * \mathrm{a}$ \\
Cortex & $128.46 \pm 3.24$ & $138.25 \pm 4.77 \mathrm{a}$ \\
Thalamus & $131.72 \pm 3.55$ & $134.55 \pm 5.22 \mathrm{~b}$ \\
\hline
\end{tabular}

*(F mol/mg tissue); a: Significant at $\mathrm{P}<0.5$; b: Non-significant at $\mathrm{P}<0.5$

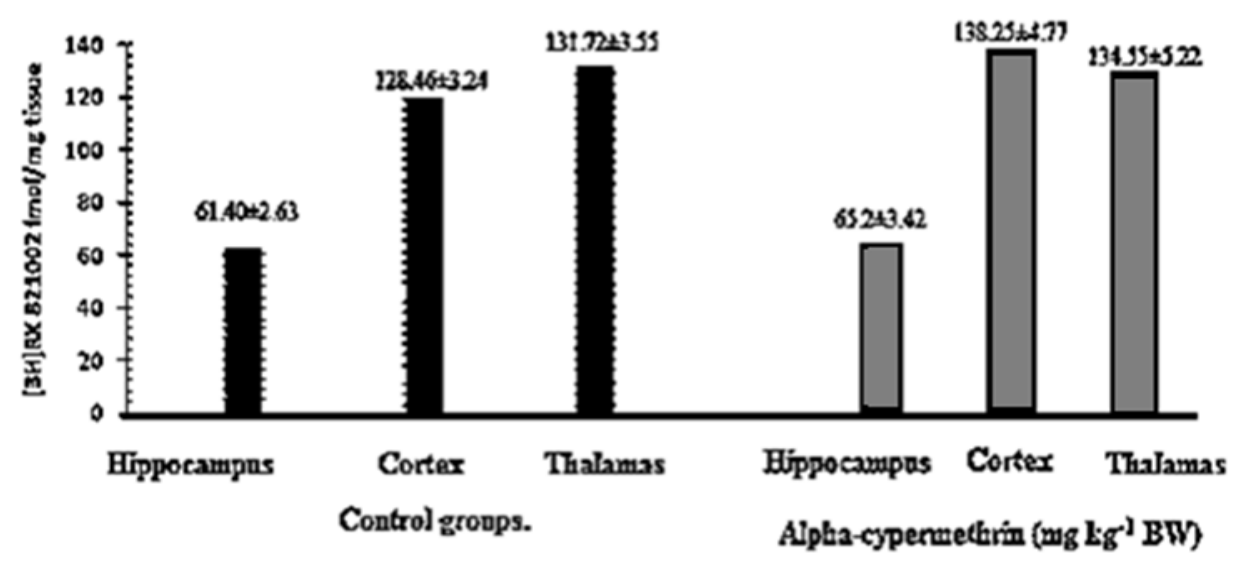

Figure 3 Effect of sub-lethal oral dose of alpha-cypermethrin on the binding [3H] RX821002 to $\alpha 2$-adrenergic receptors in hippocampus, cortex and thalamus of the rat brain ( 2 hours post treatment).

\subsection{Concentrations of alpha-cypermethrin single oral sub-lethal dose in blood plasma of rats $(25 \mathrm{mg} \mathrm{kg-1} \mathrm{B}$ W)}

As shown in Table, 1 and Fig.1, Alpha-cypermethrin $25 \mathrm{mg} \mathrm{kg}^{-1} \mathrm{~B} \mathrm{~W}$ concentrations in blood plasma of rat after 1, 2, 3 and $24 \mathrm{hr}$. were $0.416 \pm 0.158 ; 0.233 \pm 0.058 ; 0.162 \pm 0.058$ and $0.257 \pm 0.158$, respectively.

It is likely that the pattern of concentration in lipid-rich tissues is due to the high lipid solubility of pyrethroid compounds. Since metabolism of pyrethroids results in products that are more water-soluble than the parent compounds, it is likely that the metabolites are less able to cross the blood-brain barrier, unless there are facilitated mechanisms for transport of pyrethroid metabolites that have not yet been characterized. 
However, these compounds are highly toxic to fish and other lower aquatic organisms [11], and their widespread use has led to toxic effects in plants, animals, and human beings.

No information was located regarding the transport of pyrethroid compounds in blood. Pyrethroids are distributed to nearly all tissues and are concentrated in tissues with high lipid contents, such as fat and nerve tissue $[12,13]$.

\subsection{Effects on the extracellular Serotonin levels in rat ventral hippocampus}

Extracellular serotonin levels \% (f mol/mg tissue) in rat ventral hippocampus at $25 \mathrm{mg} \mathrm{kg}^{-1} \mathrm{~B} . \mathrm{W}$. after 1, 2, 3 and $24 \mathrm{hr}$. were $105 \pm 4,80 \pm 7,80 \pm 4,70 \pm 4$, respectively. Alpha-cypermethrin administered acutely, at $2 \mathrm{hr}$., $3 \mathrm{hr}$. and $24 \mathrm{hr}$. after dosing, revealed significant $(P<0.05)$ increase in extracellular serotonin levels \% ( $\mathrm{fol} / \mathrm{mg}$ tissue) in rat ventral hippocampus, cortex and cortex as shown in Table 3 and Fig.3.

Alpha-cypermethrin acts as serotonin reuptake inhibitors (SRIs) in rat ventral hippocampus, cortex and thalamus at the presynaptic alpha-2 adrenergic receptors [14]. Alpha-cypermethrin administered, at $1 \mathrm{hr}$. and up to $24 \mathrm{hr}$. after dosing, revealed significant increase in $\alpha_{2}$-adrenergic receptors in all brain regions (ventral hippocampus ,cortex and cortex), as evidenced by significant $(P<0.05)$ increased number of $\left[{ }^{3} \mathrm{H}\right] \mathrm{RX} 821002$ (binding sites in such brain regions)].

Our findings revealed that, Alpha-cypermethrin acts as nor-epinephrine reuptake inhibitors (NRIs) in rat ventral hippocampus, cortex and thalamus at the presynaptic alpha-2 adrenergic receptors [14]. The mechanism by which Alpha-cypermethrin works is not clear (it might prevent the reuptake of norepinephrine by the presynaptic neuron). Alpha-cypermethrin administered, at $2 \mathrm{hr}$. and up to $24 \mathrm{hr}$. after dosing, revealed significant increase in $\alpha_{2}$-adrenergic receptors in all brain regions (ventral hippocampus and cortex ), as evidenced by significant $(P<0.05)$ increased number of [ $\left.{ }^{3} \mathrm{H}\right] \mathrm{RX} 821002$ (binding sites in the hippocampus and cortex )] [15].

\subsection{Effects on the extracellular Noradrenalin levels in rat ventral hippocampus.}

Extracellular NA levels \% (f mol/mg tissue) in rat ventral hippocampus at $25 \mathrm{mg} \mathrm{kg}^{-1} \mathrm{~B} . \mathrm{W}$. after 1, 2, 3 and $24 \mathrm{hr}$. were $300 \pm 10,450 \pm 14,400 \pm 12,400 \pm 11$, respectively as shown in Table, 2and Fig.2. Alpha-cypermethrin administered acutely, at $2 \mathrm{hr}$.,3hr. and $24 \mathrm{hr}$. after dosing, revealed significant $(P<0.05)$ increase in extracellular NA levels \% (f $\mathrm{mol} / \mathrm{mg}$ tissue) in rat ventral hippocampus and cortex.

Our findings revealed that, Alpha-cypermethrin acts as nor-epinephrine reuptake inhibitors (NRIs) in rat ventral hippocampus, cortex and thalamus at the presynaptic alpha-2 adrenergic receptors [14]. The mechanism by which Alpha-cypermethrin works is not clear (it might prevent the reuptake of norepinephrine by the presynaptic neuron). Alpha-cypermethrin administered, at $2 \mathrm{hr}$. and up to $24 \mathrm{hr}$. after dosing, revealed significant increase in $\alpha_{2}$-adrenergic receptors in all brain regions (ventral hippocampus and cortex ), as evidenced by significant $(P<0.05)$ increased number of $\left[{ }^{3} \mathrm{H}\right] \mathrm{RX} 821002$ binding sites in the hippocampus and cortex [15].

Cypermethrin has other effects on aminobutyric acid receptor. It inhibits excitement and convulsions. In addition, it prevents the absorption of calcium (uptake) from the nerves and inhibits monoamine oxidase, an enzyme that breaks down neurotransmitters [16]. Cypermethrin also affects an enzyme not directly related to the nervous system, adenosine triphosphatase. It is involved in the production of cellular energy, the transfer of metal atoms, and muscle cramps and contractions.

Pyrethroid-dependent neurotransmitter release from presynaptic nerve terminals in the brain was first documented in rats treated with deltamethrin [17]. Treatment of deltamethrin resulted in a significant reduction in acetylcholine levels in the entire brain, and most importantly in the cerebellum. In contrast, cismethrin did not produce any significant reduction in acetylcholine levels [17].

Other effects of pyrethroids (deltamethrin and cypermethrin) in the cerebellum include increases in cyclic guanosine monophosphate levels $[17,18,19,20]$ and enhanced calcium-dependent neurotransmitter release by fenvalerate from rabbit striatal slices but not from hippocampal slices.

Pyrethroids also increased the levels of some amino acid neurotransmitters and metabolites of monoamine neurotransmitters in the brain. The release of neurotransmitters is a highly organized event dependent on external calcium influx via voltage-sensitive calcium channels associated with the plasma membrane of the presynaptic nerve terminals [21]. 
The histopathological changes of brain (Fig.4 a, b, c and d) in the acute sub-lethal-dose group (25 mg kg ${ }^{-1}$ BW) were congestion, slight neuronal vacuolation ${ }_{\llcorner}$hemorrhages, extracellular brain edema and focal glial cells infiltrations (Gliosis) [22.23].

In cypermethrin-intoxicated rats, pyknosis of the Purkinje cells and disappearance of some of the cells in the cerebellum was observed by Luty et al. [24]. Pyknosis of neurons was observed cypermethrin-intoxication in rats. Congestion and degenerative changes in the brain were reported in calves and rats, respectively. Manna et al., (2004a and b) [23,25] reported congestion and hemorrhages in the brain of rats intoxicated with single and repeated doses of cypermethrin. In cypermethrin-intoxicated rats, Grewal et al. [26] observed neuronal degeneration and necrosis in the cerebrum. Pesticide exposure is recognized as a risk factor for Alzheimer's disease (AD). The signs of AD-like pathology upon exposure to cypermethrin, it reported that, impairs neurodevelopment. Cypermethrin (10 and $\left.25 \mathrm{mg} / \mathrm{kg}^{-1}\right)$ increased the key proteins of $\mathrm{AD}$, amyloid beta $(\mathrm{A} \beta)$, and phospho-tau, in frontal cortex and hippocampus as early as postnatal day 45 [27].

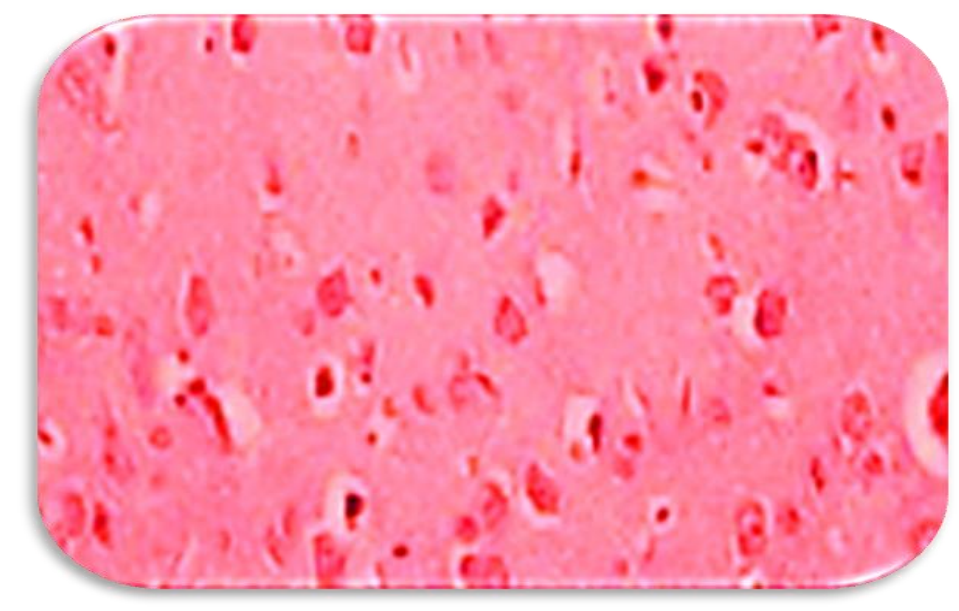

Figure 4a Brain of rat showing normal histological structures (H\&E, X 400).

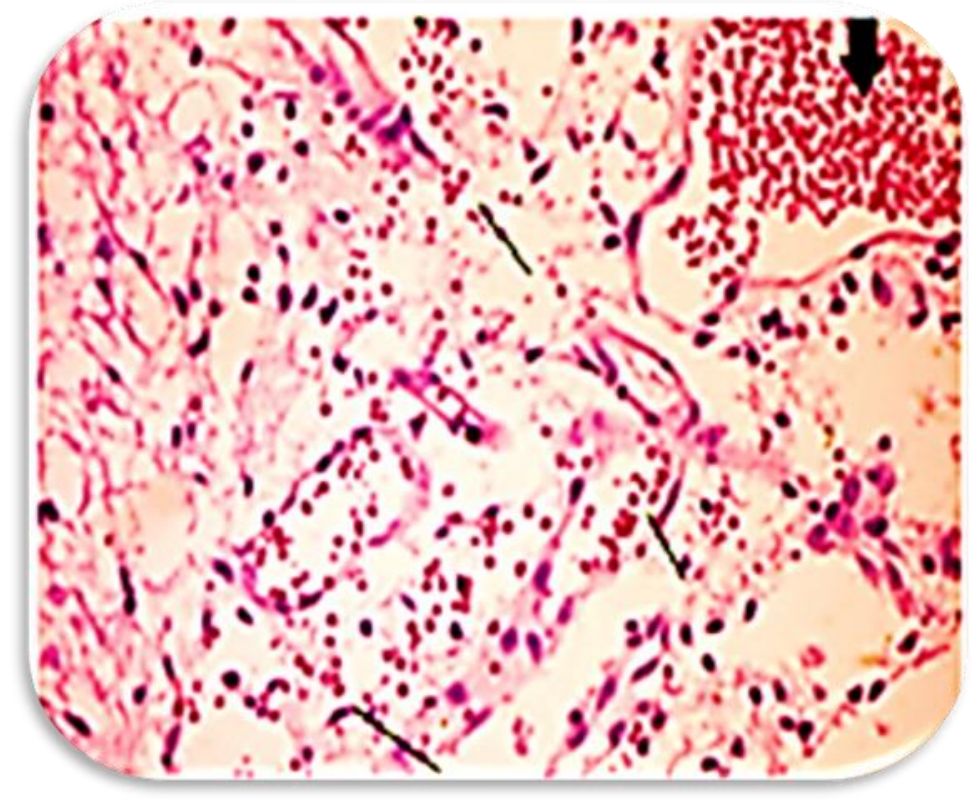

Figure $\mathbf{4 b}$ Brain of rat showing Severe edema, congestion (arrowhead) and hemorrhage (arrows) (H\&E, X200). 


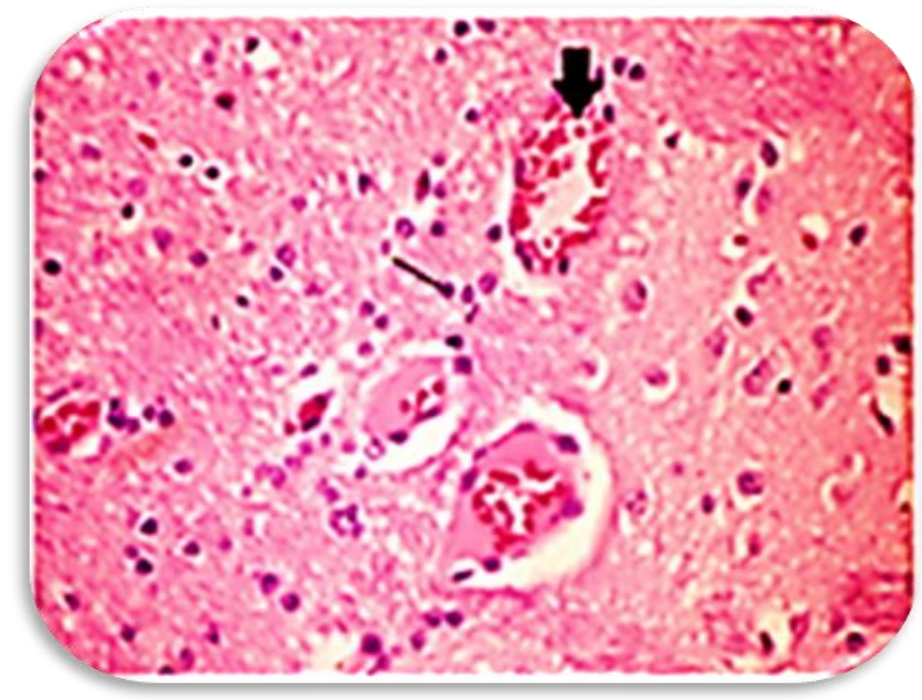

Figure 4c Brain of rat showing congestion and gliosis (arrows) (H\&E,X200).

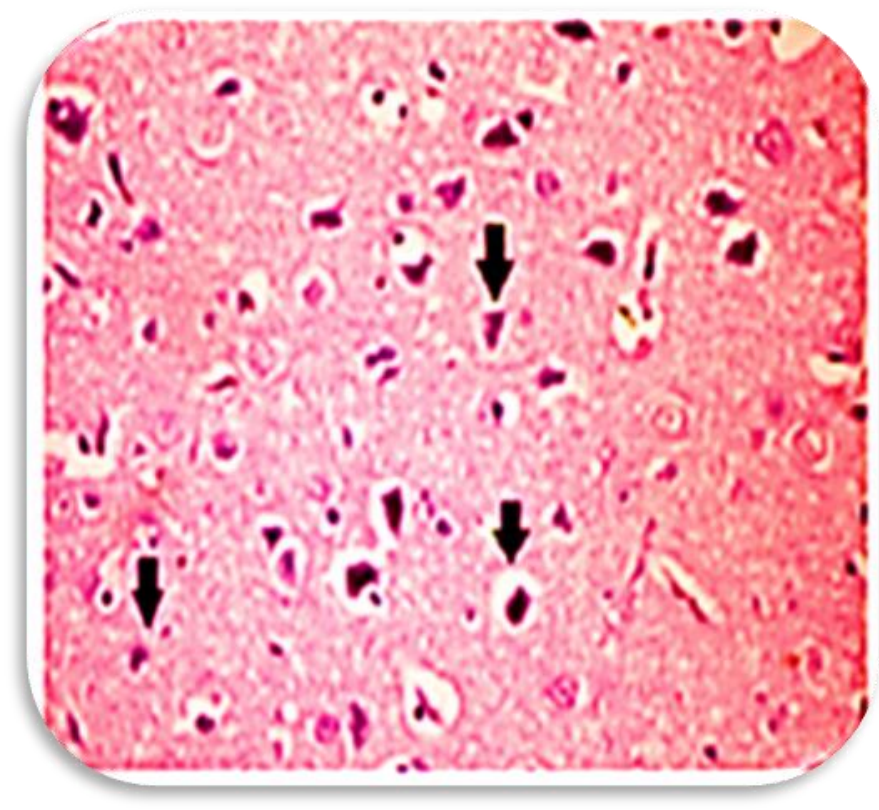

Figure 4d Brain of rat showing degenerative neurons (arrows) (H\&E, X200).

\section{Conclusion}

A single sub-acute lethal -oral dose of Alpha-Cypermethrin (25 $\mathrm{mg} \mathrm{kg}^{-1}$ ) in rat were result in lesions of brain tissues: gliosis, perineuronal vacuolation, perivascular vacuolation, and neuronal degeneration. In Addition to, increasing of the extracellular serotonin and noradrenalin levels in ventral hippocampus, cortex and thalamus. Alpha-Cypermethrin acts as nor-epinephrine reuptake inhibitors (NRIs) and serotonin reuptake stimulator in rat brain. These findings are of interest, since elderly humans experiencing transient ischemic attacks are chronically exposed to cypermethrin, used for household pest control or via contaminated fruits, vegetables and drinking water. 


\section{Compliance with ethical standards}

\section{Acknowledgments}

This research was sponsored by Department of Animal Hygiene and Environmental Pollution (Faculty of Veterinary Medicine, Cairo University). We thank Dr. Farag Mahmoud Malhat Central Laboratory of Pesticides, Centre of Agricultural Research, Egypt.

\section{Disclosure of conflict of interest}

The authors declare that they have no competing interests.

\section{Statement of ethical approval}

All efforts were made to minimize the number of animals and their suffering in this study through following the guidelines released by Cairo university policy on Animal Care and Use.

\section{References}

[1] Gotoh Y, Kawakami M, Matsumoto N and Okada Y. (1998). Permethrin emulsion ingestion: clinical manifestations and clearance of isomers. Clin. Toxicol, 36, 57-61.

[2] He, JJ, Chen F, Liu, R, Song L, Chang HC and Wang XR. (2006). Fenvalerate-induced alterations in calcium homeostasis in rat ovary. Biomed. Environ. Sci, 19, 15-20.

[3] Eells JT, Bandettini PA, Holman PA and Propp JM. (1992). Pyrethroid insecticide-induced alterations in mammalian synaptic membrane potential. J. Pharmacol. Exp. Ther, 262, 1173-1181.

[4] Crofton KM and Reiter LW. (1987). Pyrethroid insecticides and the gamma-aminobutyric acid A receptor complex: Motor activity and the acoustic startle response in the rat. J. Pharmacol. Exp. Ther, 243, 946-954.

[5] Lawrence LJ and Casida JE. (1983). Stereospecific action of pyrethroid insecticides on the 7-aminobutyric acid receptor-ionophore complex, Science, 221, 1399-1401.

[6] Bloomquist JR, Adams PM and Soderlund DM. (1986). Inhibition of $\gamma$-aminobutyric acid-stimulated chloride flux in mouse brain vesicles by polychlorocycloalkane and pyrethroid insecticides. Neurotoxicology, 7(3), 11-20.

[7] Vega SS. (1994). Note on the toxicity of pesticides used in tropical crops. Ciencias Ambientales., 11, 181.

[8] Bloms-Funke P, Dremencov E, Cremers TIFH and Tzschentke TM. (2011). Tramadol increases extracellular levels of serotonin and noradrenalin as measured by in vivo microdialysis in the ventral hippocampus of freely moving rats, Neurosci Lett, 490(3), 191-5.

[9] Karalliede L and Senanayake N. (1999). Organophosphate insecticide poisoning. J. Int. Fed. Clin. Chem, 11, 1.

[10] SAS. (2000). (Statistical Analysis System, Version 9.2): SAS Institute Inc., Cary, NC 27513-2414 USA

[11] Brown SK, Ames RG and Mengle DC. (1989). Occupational illness from cholinesterase inhibiting pesticides among agriculture pesticide applicators in California. Arch. Environ. Health, 44 (1), 34.

[12] Anadón A, Martinez-LarraZaga MR and Díaz MJ. (1991b). Toxicokinetics of permethrin in the rat. Toxicol Appl Pharmacol, 110, 1-8.

[13] Anadón A, Martinez-LarraZaga MR and Fernandez-Cruz ML. (1996). Toxicokinetics of deltamethrin and its 4'HO-metabolite in the rat. Toxicol Appl Pharmacol, 141, 8-16.

[14] (NASSAs). (2012). The mechanism of action of noradrenergic and specific serotonergic antidepressants. CNS forum.

[15] Kaoud HA, Hellal MH, Farag MM, Sherein S, Ibtesam AE and Ashour H. (2013). Effects of Acute Sub-lethal Dose of Tramadol on $\alpha 2$-Adrnergic Receptors and Liver Histopathology in Rat. Global Journal of Current Research, 1(2), 70-76.

[16] El-Toukhy MA and Girgis RS. (1993). In vivo and in vitro studies on the effect of larvin and cypermethrin on adenosine triphosphatase activity of male rats. J Environ Sci Health, B 28(5), 599-619. 
[17] Aldridge WN, Clothier B, Forshaw P, et al. (1978). The effect of DDT and pyrethroids cismethrin and decamethrin on the acetyl choline and cyclic nucleotide content of rat brain. Biochem Pharmacol., 27, 1703-1706.

[18] Lock EA and Berry PN. (1981). Biochemical changes in the rat cerebellum following cypermethrin administration. Toxicol. Appl. Pharmacol, 59(3), 508-514.

[19] Brodie ME and Aldridge WN. (1982). Elevated cerebellar cyclic GMP levels during the deltamethrin-induced motor syndrome, Neurobehav Toxicol Teratol, 4, 109-113.

[20] Brodie ME and Opacka J. (1987). Dissociation between circling behaviour and striatal dopamine activity following unilateral deltamethrin administration of rats. Naun. Schmied. Arch. Pharmacol, 331(4), 341-346.

[21] Llinas RR. (1982). Calcium in synaptic transmission. Sci. Am, 247(4), 56-65.

[22] Khan A, Faridi HA, Ali M, Khan MZ, Siddique M, Hussain I and Ahmed M. (2009). Effects of cypermethrin on some clinico- hemato- biochemical and pathological parameters in male dwarf goats (Capra hircus). Exp Toxicol Pathol, 61, 151-60.

[23] Manna S, Bhattacharya D, Basak DK and Mandal TK. (2004). Single oral dose toxicity study of á cypermethrin in rats. Indian J Pharmacol, 36, 25-8.

[24] Luty S, Latuszynska J, Halliop J, Tochman A, Obu Chowska D, Prazylepa E and Korezak E. (1998). Toxicity of dermally applied alpha cypermethrin in rats. Ann Agric Environ Med, 5, 109-15.

[25] Manna S, Bhattacharyya D, Mandal TK and Das S. (2004b). Repeated dose toxicity of alpha-cypermethrin in rats, J. Vet. Sci, 5(3), 241-245.

[26] Grewal KK, Sandhu GS, Kaur RR, Brar RS and Sandhu HS. (2010). Toxic impact of cypermethrin on behaviour and histology of certain tissues of albino rats. Toxicol Intl, 17, 94-8.

[27] Shailendra SK, Mishra J, Abbas S and Bandyopadhyay S. (2016). Cypermethrin Stimulates GSK3 $\beta$-Dependent A $\beta$ and p-tau Proteins and Cognitive Loss in Young Rats: Reduced HB-EGF Signaling and Downstream Neuroinflammation as Critical Regulators. Molecular Neurobiology, 53, 968-982.

\section{How to cite this article}

Kaoud HA, Elsaied AH and Khalil MA. (2020). Effect of alpha-cypermethrin on serotonin, nor-epinephrine and brain changes in rats. GSC Advanced Research and Reviews, 4(1), 69-77. 